\title{
Preoperative Low Weight Affects Long-term Outcomes Following Curative Gastrectomy for Gastric Cancer
}

\author{
SHUHEI KOMATSU, TOSHIYUKI KOSUGA, TAKESHI KUBOTA, KAZUMA OKAMOTO, \\ HIROTAKA KONISHI, ATSUSHI SHIOZAKI, HITOSHI FUJIWARA and EIGO OTSUJI
}

\author{
Division of Digestive Surgery, Department of Surgery, Kyoto Prefectural University of Medicine, Kyoto, Japan
}

\begin{abstract}
Background/Aim: A recent nationwide survey using the National Clinical Database in Japan identified a high proportion of low-weight patients, who are defined as low body mass index (BMI) patients, in comparison with Western countries. This study was designed to investigate the influence of low BMI on short- and long-term outcomes after curative gastrectomy for gastric cancer. Patients and Methods: Overall, 1,281 consecutive gastric cancer patients, who underwent curative gastrectomy with radical lymphadenectomy from 1997 through 2012 were retrospectively analyzed. Low BMI and non-low BMI were defined as a BMI $<18.5$ and $B M I>18.5$ $\mathrm{kg} / \mathrm{m}^{2}$, respectively. Results: Compared to patients with BMI higher than 18.5, those with $B M I<18.5$ had a significantly shorter duration of surgery $(p<0.001)$ and tended to have lower blood loss $(p=0.058)$. There was no difference in preoperative serum albumin level $(p=0.592)$ and the incidence in postoperative abdominal infection complications $(p=0.925)$ between the two groups. Whereas, BMI $<18.5$ was significantly associated with female gender, anemia, deeper tumor depth and nodal metastasis. Univariate and multivariate analyses revealed that the $B M I<18.5$ was an independent poor prognostic factor for overall survival [ $p=0.010$, HR 1.6 (95\%CI=1.32-2.30)]. Concerning recurrence, the cumulative incidence rate was significantly higher in patients with $B M I<18.5$ than those without $(p=0.045)$. Conclusion: Low weight did not have adverse effects on short-term outcomes including postoperative complications. However, there was a negative prognostic impact of low BMI, suggesting the
\end{abstract}

Correspondence to: Shuhei Komatsu, MD, FACS, Division of Digestive Surgery (Gastric Surgery Division), Department of Surgery, Kyoto Prefectural University of Medicine, 465 Kajii-cho, Kawaramachihirokoji, Kamigyo-ku, Kyoto 602-8566, Japan. Tel: +81 752515527, Fax: +81 752515522, e-mail: skomatsu@koto.kpum.ac.jp

Key Words: Low weight, body mass index, low BMI, short-term outcome, long-term outcome, prognosis, gastric cancer. requirement of meticulous treatments and follow-up in these gastric cancer patients.

Body mass index (BMI) is an indicator of underweight, normal weight and overweight as well as of the prevalence of various diseases and associated outcomes (1, 2). Individuals with BMI less than 18.5, BMI between 18.5 and 25 and BMI over 25 are considered underweight, normal weight and overweight, respectively. Recently, high BMI as a disease entity imposes a major healthcare burden in Japan, US and other societies, and more than $20 \%$ of east Asia and $60 \%$ of the US adult population have high BMI. High BMI has become a significant global problem (3). Regarding gastric cancer patients, high BMI has been reported as a crucial risk factor for postoperative complications in previous Japanese and Western country studies (4-8).

The prevalence and degree of a high BMI are increasing in Asian countries due to Westernization of diet and lifestyle. However, there still exists a vast difference in BMI distribution between Asian and Western countries. Namely, east Asian population including Japanese is generally slender, with a lower BMI than Westerners. In most of Asian countries, the average BMI is below $25 \mathrm{~kg} / \mathrm{m}^{2}$, which is the cutoff value that the World Health Organization (WHO) uses to define overweight individuals (9). Also, a recent nationwide survey using the National Clinical Database in Japan identified high proportion of preoperative low BMI patients in comparison with Western countries (10). Nevertheless, until now, only a few studies have investigated the clinical impact of preoperative low BMI on gastric cancer patients $(11,12)$ and its clinical features are still to be defined.

The purpose of the present study was to investigate whether preoperative low BMI is associated with postoperative short-term and long-term outcomes. The results of our study may provide evidence that the preoperative low BMI may not affect short-term outcomes including postoperative complications, but affect long-term prognostic outcomes, suggesting the requirement of meticulous treatments and follow-up in those patients with gastric cancer. 


\section{Patients and Methods}

Patients and operative procedures. Between 1997 and 2012, 1281 consecutive gastric cancer patients underwent curative gastrectomy with radical lymphadenectomy at the Department of Digestive Surgery, Kyoto Prefectural University of Medicine. Patients with Stage IV cancer were excluded from this study. Patients underwent preoperative assessments including gastric endoscopy, computed tomography (CT) scans, and laboratory tests. Based on the preoperative diagnosis, total or distal gastrectomy and appropriate lymphadenectomy was performed, mainly according to the Japanese guidelines for the treatment of gastric cancer $(13,14)$. Patients with clinical T1 and N0 tumors underwent D1 or D1+ lymphadenectomy whereas patients with clinical T2 or more advanced tumors and/or those with $\mathrm{N} 1$ or more advanced tumors underwent D2 or D2+ lymphadenectomy. In the D2 dissection, the perigastric lymph nodes and all second-tier lymph nodes were completely retrieved. Depending on the location of the tumor, lymphadenectomy was added along the distal side of the splenic artery (No.11d) and at the splenic hilum (No.10), together with splenectomy or splenectomy with distal pancreatectomy $(14,15)$.

Resected specimens were examined and evaluated by pathologists based on classifications of the 14th JCGC (16) and the 7th TNM staging manual (17). As a result, 709 patients were staged as pStage I, 236 as pStage II and 336 as pStage III. All enrolled patients underwent pathologically or macroscopic curative resection (R0). Histological types were classified as differentiated (papillary adenocarcinoma, or moderately or well-differentiated adenocarcinoma) or undifferentiated (poorly differentiated or undifferentiated adenocarcinoma, signet-ring cell carcinoma, or mucinous adenocarcinoma) based on the 14th JCGC (16).

Assessment of clinical impact of low BMI in gastric cancer. To evaluate the clinical impact of low BMI, we firstly investigated survival curves according to each category of BMI in all stage and stage II-III gastric cancer patients (Figure 1). Secondly, survival rate difference and cumulative recurrence ratio difference between low BMI and non-low BMI were investigated (Figure 2). Thirdly, the clinicopathological factors associated with low BMI (Table I) and multivariate analysis were investigated using Cox's proportional hazard model (Table II).

Statistical analysis. The $\chi^{2}$ test and Fisher's exact probability test were performed for categorical variables, while the Student's $t$-test and Mann-Whitney $U$-test for unpaired data of continuous variables were performed to compare clinicopathological characteristics between the two groups. Survival curves were estimated using the Kaplan-Meier method, and statistical differences were examined using the log-rank test. Univariate and multivariate survival analyses were performed using the likelihood ratio test of the stratified Cox proportional hazards model and $p<0.05$ was considered statistically significant.

\section{Results}

Comparison of overall survival and cumulative recurrence ratio according to each BMI level in gastric cancer. Figure 1 shows overall survival curves according to each BMI level in gastric cancer patients of all pathological stages (A) and pathological stage II-III (B). The number of patients in each BMI group was 214 (16.7\%) with $\mathrm{BMI}>25,921$ (71.9\%) with BMI between 18.5 and 25 and 146 (11.4\%) with $\mathrm{BMI}<18.5$. The 5 -year survival rates of all-stage patients with i) $\mathrm{BMI}>25$, ii) $18.5<\mathrm{BMI}<25$ and iii) $\mathrm{BMI}<18.5$ were i) $78.0 \%$, ii) $73.8 \%$ and iii) $63.4 \%$, respectively. Regarding stage II-III patients, the 5-year survival rates of patients with i) $\mathrm{BMI}>25$, ii) $18.5<\mathrm{BMI}<25$ and iii) $\mathrm{BMI}<18.5$ were i) $51.3 \%$, ii) $44.2 \%$ and iii) $33.3 \%$, respectively. These data suggest that preoperative low BMI was associated with poor survival independent of pathological stage.

Figure 2 shows that comparison of overall survival and cumulative recurrence ratio between patients with $\mathrm{BMI}>18.5$ and $\mathrm{BMI}<18.5$ in gastric cancer. Patients with $\mathrm{BMI}<18.5$ had significantly poorer prognosis than those with $\mathrm{BMI}>18.5$ $(p=0.010)$. The cumulative incidence of recurrence rate was significantly higher in patients with $\mathrm{BMI}<18.5$ than those without $(p=0.045)$. There was no difference of recurrence patterns between both groups.

Comparison of clinicopathological characteristics between patients with the BMI>18.5 and BMI<18.5 in gastric cancer. Table I shows the comparison of clinicopathological characteristics between the two groups. Compared to patients with the $\mathrm{BMI}>18.5$, those with the $\mathrm{BMI}<18.5$ had a significantly shorter duration of surgery $(p<0.001)$ and tended to have lower blood loss $(p=0.058)$. There was no difference of preoperative serum albumin level $(p=0.592)$ and the incidence in postoperative abdominal infection complications $(p=0.925)$ between both groups. Whereas, $\mathrm{BMI}<18.5$ was significantly associated with female $(p<0.001)$, anemia $(p=0.014)$, deeper tumor depth $(p=0.001)$ and nodal metastasis $(p=0.018)$.

Prognostic impact of preoperative low BMI. Next, the prognostic impact of preoperative low BMI was investigated. Univariate and multivariate analyses using Cox's proportional hazards model revealed that preoperative albumin of less than $3.0 \mathrm{~g} / \mathrm{dl}$, blood loss during surgery of more than $250 \mathrm{ml}$, abdominal infectious complications which are classified as being more than grade II in the Clavien-Dindo classification, pT2 or greater, nodal metastasis and the $\mathrm{BMI}<18.5[p=0.010$, $\mathrm{HR}=1.6(95 \% \mathrm{CI}=1.32-2.30)]$ was an independent poor prognostic factor for overall survival (Table II).

\section{Discussion}

Several recent studies demonstrated that host-related factors have a great influence on the prognosis of gastric cancer patients based on inflammation status (18), age and comorbidity (19), malnutrition (20) and complications $(21,22)$. Whereas, preoperative low BMI condition has received minor attention in the risk analysis for patients with gastric cancer, 

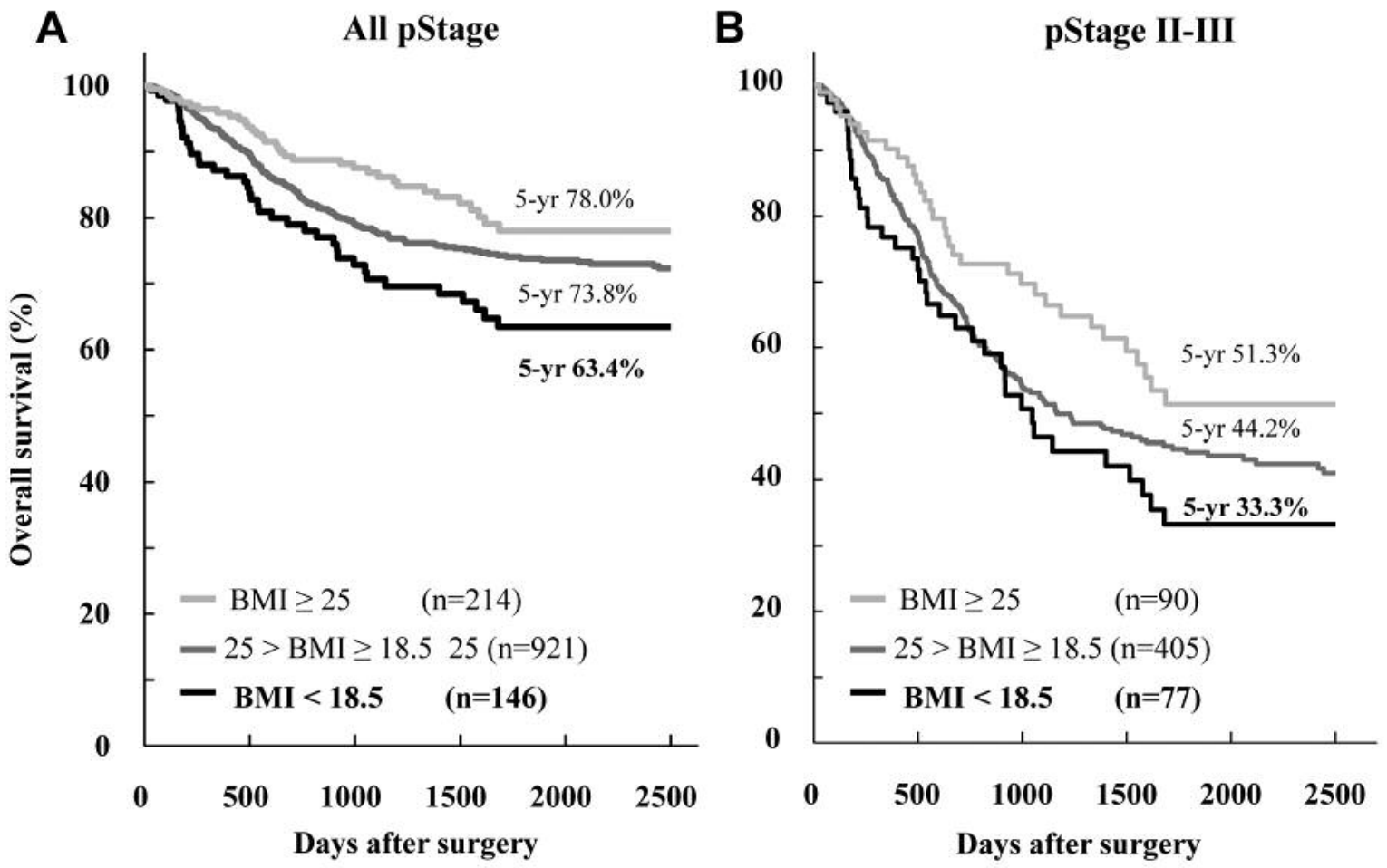

Figure 1. Comparison of overall survival curves according to BMI level in gastric cancer. Overall survival curves according to BMI level in gastric cancer patients of all pathological stages (A) and pathological stage II-III (B).
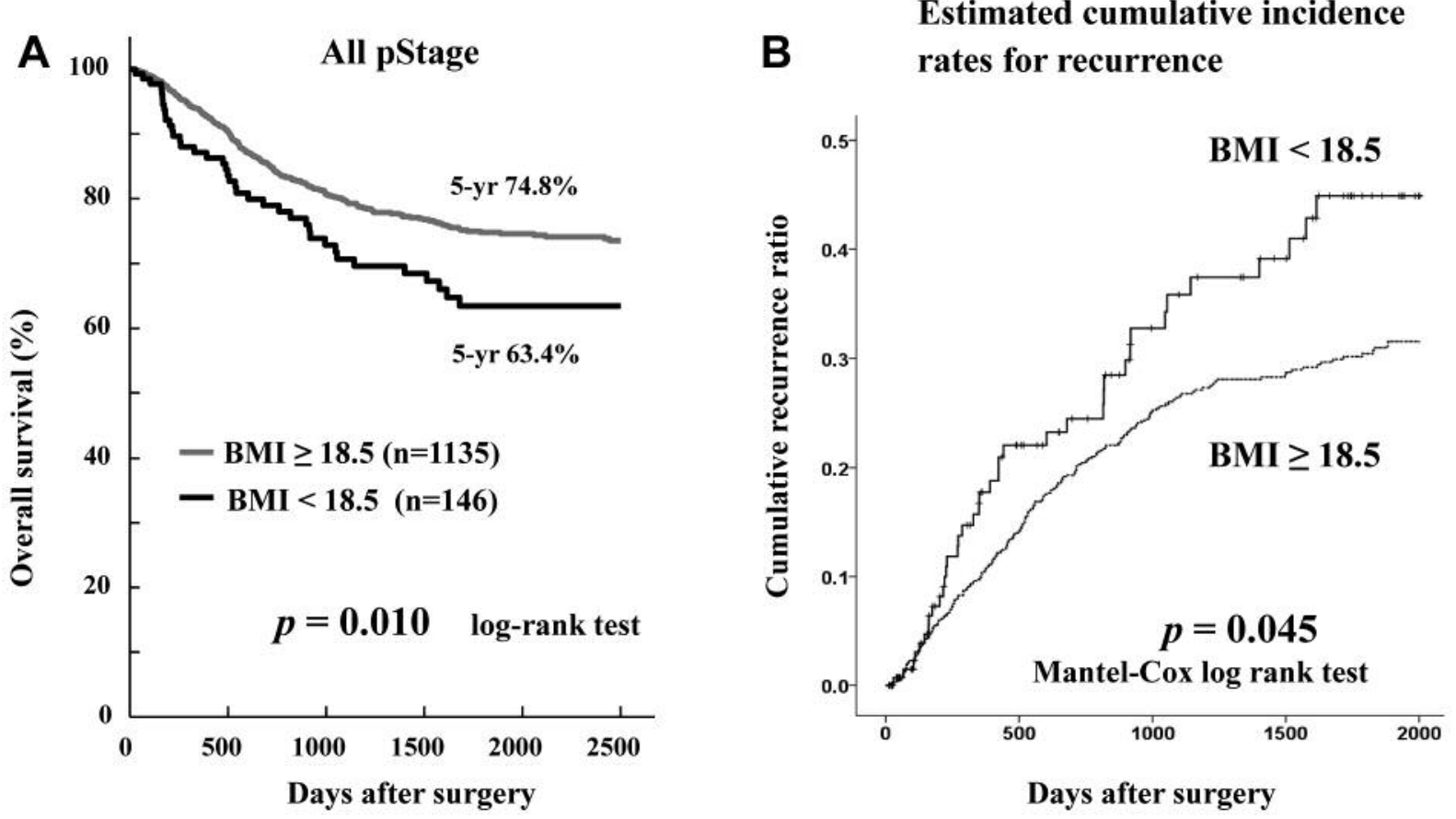

Figure 2. Comparison of overall survival and cumulative recurrence ratio between patients with BMI $>18.5$ and BMI $<18.5$ in gastric cancer. (A) Patients with the BMI<18.5 significantly had poorer prognosis than those with BMI>18.5 $(p=0.010)$. (B) The cumulative incidence of recurrence rate was significantly higher in patients with the BMI $<18.5$ than those without $(p=0.045)$. 
Table I. Association between clinicopathologic characteristics and preoperative low BMI in gastric cancer.

\begin{tabular}{|c|c|c|c|c|c|c|}
\hline \multirow[b]{3}{*}{ Total } & \multirow[t]{2}{*}{$\mathrm{n}$} & \multicolumn{4}{|c|}{ Preoperative low BMI } & \multirow[t]{2}{*}{$p$-Value* } \\
\hline & & \multicolumn{2}{|c|}{$\mathrm{BMI}<18.5$} & \multicolumn{2}{|c|}{$\mathrm{BMI} \geq 18.5$} & \\
\hline & 1281 & 146 & & 1135 & & \\
\hline \multicolumn{7}{|l|}{ Gender } \\
\hline Male & 872 & 77 & $53 \%$ & 795 & $70 \%$ & \\
\hline Female & 409 & 69 & $47 \%$ & 340 & $30 \%$ & $<0.0001$ \\
\hline \multicolumn{7}{|l|}{ Age $(y)$} \\
\hline$<75$ & 1023 & 108 & $74 \%$ & 915 & $81 \%$ & \\
\hline$\geq 75$ & 258 & 38 & $26 \%$ & 220 & $19 \%$ & 0.0595 \\
\hline \multicolumn{7}{|l|}{ Location } \\
\hline Upper & 326 & 37 & $25 \%$ & 289 & $25 \%$ & \\
\hline Middle or Lower & 955 & 109 & $75 \%$ & 846 & $75 \%$ & 0.9749 \\
\hline \multicolumn{7}{|c|}{ Preoperative hemoglobin (g/dl) } \\
\hline$<8.0$ & 24 & 7 & $5 \%$ & 17 & $1 \%$ & \\
\hline$\geq 8.0$ & 1257 & 139 & $95 \%$ & 1118 & $99 \%$ & 0.0146 \\
\hline \multicolumn{7}{|c|}{ Preoperative albumin $(\mathrm{g} / \mathrm{dl})$} \\
\hline$<3.0$ & 16 & 3 & $2 \%$ & 13 & $1 \%$ & \\
\hline$\geq 3.0$ & 1265 & 143 & $98 \%$ & 1122 & $99 \%$ & 0.5923 \\
\hline \multicolumn{7}{|c|}{ Duration of suegery (min) } \\
\hline$<230$ & 322 & 63 & $43 \%$ & 259 & $23 \%$ & \\
\hline$\geq 230$ & 959 & 83 & $57 \%$ & 876 & $77 \%$ & $<0.0001$ \\
\hline \multicolumn{7}{|l|}{ Blood loss (ml) } \\
\hline$<250$ & 590 & 78 & $53 \%$ & 512 & $45 \%$ & \\
\hline$\geq 250$ & 691 & 68 & $47 \%$ & 623 & $55 \%$ & 0.0577 \\
\hline \multicolumn{7}{|c|}{ Abdominal infectious complications } \\
\hline absence & 1182 & 135 & $92 \%$ & 1047 & $92 \%$ & \\
\hline presence & 99 & 11 & $8 \%$ & 88 & $8 \%$ & 0.9256 \\
\hline \multicolumn{7}{|l|}{ Histology } \\
\hline Differentiated & 638 & 62 & $42 \%$ & 576 & $51 \%$ & \\
\hline Undifferentiated & 643 & 84 & $58 \%$ & 559 & $49 \%$ & 0.0595 \\
\hline \multicolumn{7}{|c|}{ Lympahtic invasion (ly) } \\
\hline ly0 & 711 & 71 & $49 \%$ & 640 & $56 \%$ & \\
\hline ly $1-3$ & 570 & 75 & $51 \%$ & 495 & $44 \%$ & 0.0758 \\
\hline \multicolumn{7}{|l|}{ Venous invasion (v) } \\
\hline v0 & 893 & 93 & $64 \%$ & 800 & $70 \%$ & \\
\hline v1-3 & 388 & 53 & $36 \%$ & 335 & $30 \%$ & 0.0930 \\
\hline \multicolumn{7}{|l|}{ TNM classification } \\
\hline \multicolumn{7}{|l|}{ pT categories } \\
\hline $\mathrm{T} 1$ & 653 & 65 & $45 \%$ & 588 & $52 \%$ & \\
\hline T3-4 & 628 & 81 & $55 \%$ & 547 & $48 \%$ & 0.0973 \\
\hline \multicolumn{7}{|l|}{$\mathrm{pN}$ categories } \\
\hline NO & 812 & 84 & $58 \%$ & 728 & $64 \%$ & \\
\hline N1-3 & 469 & 62 & $42 \%$ & 407 & $36 \%$ & 0.1188 \\
\hline \multicolumn{7}{|l|}{ pStege } \\
\hline I & 709 & 69 & $47 \%$ & 640 & $56 \%$ & \\
\hline II & 236 & 24 & $16 \%$ & 212 & $19 \%$ & \\
\hline III & 336 & 53 & $37 \%$ & 283 & $25 \%$ & 0.0130 \\
\hline
\end{tabular}

$p$-Values were calculated by Chi-square or Fisher's exact test. *Statistically significant values $(p<0.05)$ are shown in bold.

thus far. In this study, it was demonstrated that preoperative low BMI did not have adverse effects on short-term outcomes including postoperative complications. However, there was a negative impact on the long-term prognostic outcome, suggesting the requirement of meticulous treatments and follow-up in low BMI patients with gastric cancer.
Cancer cachexia has been recognized as a low weight condition associated with an increased risk of postoperative complications (23), in particular infectious complications (24). However, in the present series, it appeared that low BMI was not different from cancer cachexia and did not influence the short-term outcomes including complications 
Table II. Univariate and multivariate analyses to indentify prognostic effect of low BMI in gastric cancer.

\begin{tabular}{|c|c|c|c|c|c|c|}
\hline \multirow[t]{2}{*}{ Characteristics } & \multirow[t]{2}{*}{$\mathrm{n}$} & \multirow[t]{2}{*}{5 -yr SR (\%) } & \multirow{2}{*}{$\frac{\text { Univariate }^{\mathrm{a}}}{p \text {-Value }}$} & \multicolumn{3}{|c|}{ Multivariate ${ }^{b}$} \\
\hline & & & & HR & $95 \% \mathrm{CI}$ & $p$-Value \\
\hline \multicolumn{7}{|l|}{ Gender } \\
\hline Male & 872 & 74.6 & & 1 & & \\
\hline Female & 409 & 71.2 & 0.349 & 1.227 & $0.928-1.621$ & 0.152 \\
\hline \multicolumn{7}{|l|}{ Age (y) } \\
\hline$<75$ & 1023 & 74.8 & & 1 & & \\
\hline$>75$ & 258 & 67.2 & 0.042 & 1.117 & $0.816-1.528$ & 0.490 \\
\hline \multicolumn{7}{|l|}{ Location } \\
\hline Upper & 326 & 66.4 & & 1 & & \\
\hline Middle or Lower & 955 & 76.0 & 0.002 & 0.958 & $0.721-1.273$ & 0.768 \\
\hline \multicolumn{7}{|c|}{ Preoperative hemoglobin $(\mathrm{g} / \mathrm{dl})$} \\
\hline$<8.0$ & 24 & 49.0 & & 1 & & \\
\hline$>8.0$ & 1257 & 74.1 & 0.011 & 1.545 & $0.768-3.115$ & 0.222 \\
\hline \multicolumn{7}{|c|}{ Preoperative albumin $(\mathrm{g} / \mathrm{dl})$} \\
\hline$<3.0$ & 16 & 26.7 & & 1 & & \\
\hline$>3.0$ & 1265 & 73.2 & $<0.001$ & 0.388 & $0.192-0.786$ & 0.009 \\
\hline \multicolumn{7}{|c|}{ Duration of suegery (min) } \\
\hline$<230$ & 322 & 73.5 & & 1 & & \\
\hline$>230$ & 959 & 73.6 & 0.871 & 1.205 & $0.870-1.667$ & 0.262 \\
\hline \multicolumn{7}{|l|}{ Blood loss (ml) } \\
\hline$<250$ & 590 & 83.5 & & 1 & & \\
\hline$>250$ & 691 & 66.1 & $<0.001$ & 1.481 & $1.078-2.035$ & 0.015 \\
\hline \multicolumn{7}{|c|}{ Abdominal infectious complications } \\
\hline absence & 1182 & 75.3 & & 1 & & \\
\hline presence & 99 & 50.5 & $<0.001$ & 1.776 & $1.212-2.604$ & 0.003 \\
\hline \multicolumn{7}{|l|}{ Histology } \\
\hline Differentiated & 638 & 80.3 & & 1 & & \\
\hline Undifferentiated & 643 & 67.3 & $<0.001$ & 1.236 & $0.938-1.628$ & 0.131 \\
\hline \multicolumn{7}{|l|}{ pT categories } \\
\hline $\mathrm{T} 1$ & 653 & 97.7 & & 1 & & \\
\hline $\mathrm{T} 2-4$ & 628 & 48.9 & $<0.001$ & 9.009 & $4.348-18.51$ & $<0.001$ \\
\hline \multicolumn{7}{|l|}{$\mathrm{pN}$ categories } \\
\hline No & 812 & 93.1 & & 1 & & \\
\hline N1-3 & 469 & 42.1 & $<0.001$ & 2.652 & $1.835-3.831$ & $<0.001$ \\
\hline \multicolumn{7}{|c|}{ Preoperative low BMI } \\
\hline$>18.5$ & 1135 & 74.8 & & 1 & & \\
\hline$<18.5$ & 146 & 63.4 & 0.010 & 1.605 & $1.332-2.309$ & 0.011 \\
\hline
\end{tabular}

Statistically significant values $(p<0.05)$ are shown in bold. SR: Survival rate, HR: hazard ratio, CI: confidence interval. ${ }^{a}$ Kaplan and Meier method, and the significance was determined by log-rank test. bMultivariate survival analysis was performed using Cox's proportional hazard model.

after curative gastrectomy. When analyzing surgical factors, patients with a low-BMI had a significantly shorter duration of surgery $(p<0.001)$ and tended to have lower blood loss $(p=0.058)$. In particular, the incidences of infectious complications in the low BMI group were similar to those in the non-low BMI control group (low BMI $v s$. non-low BMI: $8 \%$ vs. $8 \%$ ). Therefore, the influence of low BMI on perioperative short-term outcomes is not detected. Also, in the nutritional condition, there was no significant difference of preoperative albumin level between low the BMI and nonlow BMI patients $(p=0.592)$. These data suggested that patients with a low BMI do not always indicate malnutrition in Japanese and Asian patients, where the majority is slender and the average BMI is below $25 \mathrm{~kg} / \mathrm{m}^{2}$. Although some low BMI patients may be due to malnutrition, low BMI should be separately evaluated from a malnutrition in the analysis of short-term outcomes.

Regarding the long-term prognostic outcomes in gastric cancer patients following curative gastrectomy, low BMI was independently associated with poor prognosis $[p=0.010$, $\mathrm{HR}=1.6(95 \% \mathrm{CI}=1.32-2.30)]$, as well as preoperative low nutrition, abdominal infectious complications, intraoperative blood loss and disease progression (Table II). Although there was no correlation between low BMI and clinical factors such 
as the preoperative low nutrition, abdominal infectious complications and intraoperative blood loss (Table I), low BMI had an adverse prognostic effect on overall survival following gastrectomy. Moreover, the cumulative incidence of recurrences was significantly higher in patients with low BMI than those without. It is still unclear which metabolic and molecular mechanisms are responsible for the relationship between low BMI and an adverse prognostic outcome, but a combination of immune, inflammatory, and metabolic processes may play an important role in the prognostic outcome (24).

Recently, postoperative body weight loss has been reported to be an independent prognostic factor for recurrence-free survival (25) and has been associated with the continuation of adjuvant chemotherapy (25, 26). Although normal weight and overweight patients could afford to lose the nutrition in reserve and immune sufficiency, low-BMI patients may suffer from malnutrition in early stage of postoperative body weight loss. The difference in nutritional reserve may be the reason of different prognosis in accordance to $\operatorname{BMI}(27,28)$. Indeed, as shown in Figure 1, overweight patients had better prognosis than those with low BMI and normal weight in both all stage and stage II-III patients. Therefore, as a treatment strategy for low-BMI patients, long-term nutritional maintenance may induce stable immune competence and suppress the recurrence derived from micrometastasis after curative surgery $(29,30)$.

Regarding postoperative nutritional strategy, Imamura et al. recently reported that supplementation with an oral elemental diet reduced postoperative weight loss in gastric cancer patients undergoing gastrectomy (31). Not only supplementation with an oral elemental diet, but also other nutritional or immune targeted treatment strategy may be necessary to reduce postoperative body weight loss and improve the poor prognosis of low-BMI patients after gastrectomy. These strategies are currently under evaluation. Also, meticulous anticancer treatments and follow-up may be needed in low-BMI patients. Nevertheless, this study had some limitations because the long accrual period of the retrospective analysis at a single institute may reflect possible variations of overall survival time. A large scale or multicenter prospective cohort study may be warranted to validate the significance of low BMI in gastric cancer treatments.

\section{References}

1 Shiwaku K, Anuurad E, Enkhmaa B, Nogi A, Kitajima K, Shimono K, Yamane Y and Oyunsuren T: Overweight japanese with body mass indexes of 23.0-24.9 have higher risks for obesityassociated disorders: A comparison of japanese and mongolians. Int J Obes Relat Metab Disord 28(1): 152-158, 2004.

2 Ogden CL, Carroll MD, Curtin LR, McDowell MA, Tabak CJ and Flegal KM: Prevalence of overweight and obesity in the united states, 1999-2004. Jama 295(13): 1549-1555, 2006.
3 Finucane MM, Stevens GA, Cowan MJ, Danaei G, Lin JK, Paciorek CJ, Singh GM, Gutierrez HR, Lu Y, Bahalim AN, Farzadfar F, Riley LM and Ezzati M: National, regional, and global trends in body-mass index since 1980: Systematic analysis of health examination surveys and epidemiological studies with 960 country-years and $9 \bullet 1$ million participants. The Lancet 377(9765): 557-567, 2011.

4 Bonenkamp JJ, Songun I, Hermans J, Sasako M, Welvaart K, Plukker JT, van Elk P, Obertop H, Gouma DJ, Taat CW et al: Randomised comparison of morbidity after $\mathrm{d} 1$ and $\mathrm{d} 2$ dissection for gastric cancer in 996 dutch patients. Lancet 345(8952): 745748, 1995.

5 Cuschieri A, Fayers P, Fielding J, Craven J, Bancewicz J, Joypaul V and Cook P: Postoperative morbidity and mortality after $\mathrm{d} 1$ and $\mathrm{d} 2$ resections for gastric cancer: Preliminary results of the mrc randomised controlled surgical trial. The surgical cooperative group. Lancet 347(9007): 995-999, 1996.

6 Kodera Y, Ito S, Yamamura Y, Mochizuki Y, Fujiwara M, Hibi $\mathrm{K}$, Ito K, Akiyama S and Nakao A: Obesity and outcome of distal gastrectomy with d2 lymphadenectomy for carcinoma. Hepatogastroenterology 51(58): 1225-1228, 2004.

7 Tsujinaka T, Sasako M, Yamamoto S, Sano T, Kurokawa Y, Nashimoto A, Kurita A, Katai H, Shimizu T, Furukawa H, Inoue S, Hiratsuka M, Kinoshita T, Arai K, Yamamura Y and Gastric Cancer Surgery Study Group of Japan Clinical Oncology G: Influence of overweight on surgical complications for gastric cancer: Results from a randomized control trial comparing d2 and extended para-aortic d3 lymphadenectomy (jogg9501). Ann Surg Oncol 14(2): 355-361, 2007.

8 Bickenbach KA, Denton B, Gonen M, Brennan MF, Coit DG and Strong VE: Impact of obesity on perioperative complications and long-term survival of patients with gastric cancer. Ann Surg Oncol 20(3): 780-787, 2013.

9 Obesity: Preventing and managing the global epidemic. Report of a who consultation. World Health Organ Tech Rep Ser 894(ixii): 1-253, 2000.

10 Ri M, Miyata H, Aikou S, Seto Y, Akazawa K, Takeuchi M, Matsui Y, Konno H, Gotoh M, Mori M, Motomura N, Takamoto S, Sawa Y, Kuwano H and Kokudo N: Effects of body mass index (bmi) on surgical outcomes: A nationwide survey using a japanese web-based database. Surg Today 45(10): 1271-1279, 2015.

11 Ejaz A, Spolverato G, Kim Y, Poultsides GA, Fields RC, Bloomston M, Cho CS, Votanopoulos K, Maithel SK and Pawlik TM: Impact of body mass index on perioperative outcomes and survival after resection for gastric cancer. J Surg Res 195(1): 74$82,2015$.

12 Migita K, Takayama T, Matsumoto S, Wakatsuki K, Tanaka T, Ito M, Kunishige T, Nakade $\mathrm{H}$ and Nakajima Y: Impact of being underweight on the long-term outcomes of patients with gastric cancer. Gastric Cancer 19(3): 735-743, 2016.

13 Nakajima T: Gastric cancer treatment guidelines in japan. Gastric Cancer 5(1): 1-5, 2002.

14 Japanese gastric cancer treatment guidelines 2010 (ver. 3). Gastric Cancer 14(2): 113-123, 2011.

15 Komatsu S, Ichikawa D, Nishimura M, Kosuga T, Okamoto K, Konishi H, Shiozaki A, Fujiwara H and Otsuji E: Evaluation of prognostic value and stage migration effect using positive lymph node ratio in gastric cancer. Eur J Surg Oncol 43(1): 203-209, 2017. 
16 Japanese classification of gastric carcinoma: 3rd english edition. Gastric Cancer 14(2): 101-112, 2011.

17 Sobin LH, Gospodarowicz MK and Wittekind C: International union against cancer. TNM classification of malignant tumours Chichester, West Sussex, UK. Hoboken. NJ, Wiley-Blackwell, 2010.

18 Kubota T, Hiki N, Nunobe S, Kumagai K, Aikou S, Watanabe R, Sano T and Yamaguchi T: Significance of the inflammationbased glasgow prognostic score for short- and long-term outcomes after curative resection of gastric cancer. J Gastrointest Surg 16(11): 2037-2044, 2012.

19 Ariake K, Ueno T, Takahashi M, Goto S, Sato S, Akada M and Naito H: E-pass comprehensive risk score is a good predictor of postsurgical mortality from comorbid disease in elderly gastric cancer patients. J Surg Oncol 109(6): 586-592, 2014.

20 Gibbs J, Cull W, Henderson W, Daley J, Hur K and Khuri SF: Preoperative serum albumin level as a predictor of operative mortality and morbidity: Results from the national va surgical risk study. Arch Surg 134(1): 36-42, 1999.

21 Tokunaga M, Tanizawa Y, Bando E, Kawamura T and Terashima M: Poor survival rate in patients with postoperative intraabdominal infectious complications following curative gastrectomy for gastric cancer. Ann Surg Oncol 20(5): 1575-1583, 2013.

22 Kiuchi J, Komatsu S, Ichikawa D, Kosuga T, Okamoto K, Konishi H, Shiozaki A, Fujiwara H, Yasuda T and Otsuji E: Putative risk factors for postoperative pneumonia which affects poor prognosis in patients with gastric cancer. International Journal of Clinical Oncology 21(5): 920-926, 2016.

23 Warnold I and Lundholm K: Clinical significance of preoperative nutritional status in 215 noncancer patients. Ann Surg 199(3): 299-305, 1984

24 Heys SD, Schofield AC, Wahle KW and Garcia-Caballero M: Nutrition and the surgical patient: Triumphs and challenges Surgeon 3(3): 139-144, 2005.

25 Kubo H, Komatsu S, Ichikawa D, Kawaguchi T, Kosuga T, Okamoto K, Konishi H, Shiozaki A, Fujiwara H and Otsuji E: Impact of body weight loss on recurrence after curative gastrectomy for gastric cancer. Anticancer Res 36(2): 807-813, 2016.
26 Aoyama T, Yoshikawa T, Shirai J, Hayashi T, Yamada T, Tsuchida K, Hasegawa S, Cho H, Yukawa N, Oshima T, Rino Y, Masuda M and Tsuburaya A: Body weight loss after surgery is an independent risk factor for continuation of s-1 adjuvant chemotherapy for gastric cancer. Ann Surg Oncol 20(6): 2000-2006, 2013.

27 Ockenga $J$ and Valentini L: Review article: Anorexia and cachexia in gastrointestinal cancer. Aliment Pharmacol Ther 22(7): 583-594, 2005.

28 Fouladiun M, Körner U, Bosaeus I, Daneryd P, Hyltander A and Lundholm KG: Body composition and time course changes in regional distribution of fat and lean tissue in unselected cancer patients on palliative care - correlations with food intake, metabolism, exercise capacity, and hormones. Cancer 103(10): 2189-2198, 2005.

29 Sietses C, Beelen RH, Meijer S and Cuesta MA: Immunological consequences of laparoscopic surgery, speculations on the cause and clinical implications. Langenbecks Arch Surg 384(3): 250$258,1999$.

30 Goldfarb Y, Sorski L, Benish M, Levi B, Melamed R and BenEliyahu S: Improving postoperative immune status and resistance to cancer metastasis: A combined perioperative approach of immunostimulation and prevention of excessive surgical stress responses. Ann Surg 253(4): 798-810, 2011.

31 Imamura H, Nishikawa K, Kishi K, Inoue K, Matsuyama J, Akamaru Y, Kimura Y, Tamura S, Kawabata R, Kawada J, Fujiwara Y, Kawase T, Fukui J, Takagi M, Takeno A and Shimokawa T: Effects of an oral elemental nutritional supplement on post-gastrectomy body weight loss in gastric cancer patients: A randomized controlled clinical trial. Ann Surg Oncol 23(9): 2928-2935, 2016.
Received June 4, 2018

Revised July 18, 2018

Accepted July 19, 2018 